\title{
Navigating the chaos of an unfolding global cycle
}

\author{
$\underline{\text { Brian Walker }}^{1,2}, \underline{\text { Stephen R. Carpenter }}^{3}, \underline{\text { Carl Folke }}^{4,5}, \underline{\text { Lance Gunderson }}^{6}, \underline{\text { Garry D. Peterson }}^{5}, \underline{\text { Marten Scheffer }}^{7}, \underline{\text { Michael Schoon }}^{8}$ \\ and Frances R. Westley ${ }^{9}$
}

\begin{abstract}
There are many calls to use the COVID 19 crisis as an opportunity for transforming to a future trajectory that is more equitable and environmentally sustainable. What is lacking is a cohesive framework for bringing these calls together. We propose that such transitions could be informed by lessons from three decades of scholarship on abrupt and surprising change in systems of humans and nature. Over time, many social-ecological systems exhibit cycles of change consisting of sequential patterns of growth, development, crisis, and reorganization. A critical phase in the cycle is the brief period after crisis when novelty and innovation can change the future trajectory. Without being prepared for this window of opportunity, deep, systemic change may be unachievable.
\end{abstract}

We propose a three-step process to identify the major drivers of the global system that need to be changed: (1) identifying what society values; (2) identifying the determinants of these valued variables; and (3) identifying the underlying drivers of the determinants and how they need to be changed. A tentative list of five such drivers are identified and discussed: (i) the economic system, (ii) homogenization, (iii) human population growth, size, and densities, (iv) consumption patterns, human ethics, and behavior, and (v) governance. They are linked to seven questions relating to how we might proceed in addressing the drivers.

If response to the crisis merely reinforces the existing system, its incompatibility with the natural world and its propensity to increase inequity and conflict will likely increase fragility and lead to another version of the present calamity. If it is a deliberately transformed system that emerges its future will depend on the reorganization process, and the way the system is guided into the future. What is needed is a deliberate, fundamental cultivation of emergence to enable transformation toward better futures in order to avoid an inevitable deepening of a system that ultimately is worse for all.

Key Words: adaptive cycle; COVID 19; drivers; global; governance; gridlock; renewal; transformation

\section{INTRODUCTION}

The COVID-19 crisis has focused attention on the unsustainability of the world order and opened a window of opportunity for change. However, a plausible alternative needs a framework for bringing together the many disparate calls, and we suggest a resilience lens provides such a structure. A key feature of resilience is the existence of threshold levels in the controlling variables beyond which the system continues to move away from, rather than back to what it was like before. Crossing a threshold is often due to an external shock. Under which conditions could the COVID shock move the world onto a novel pathway that is more sustainable than the current one? What does resilience theory suggest about the possibilities to deliberately transform into a new kind of system at this point?

\section{CYCLES OF GRIDLOCK AND RENEWAL}

How, where, and when to intervene?

Ecological, social, economic, and other complex systems exhibit characteristic four-phase cycles of change (Gunderson and Holling 2002; Fig. 1). The "foreloop" ( $\mathrm{r}$ and K) is reasonably predictable and slow. The "backloop" (collapse [ $\Omega]$ and reorganization $[\alpha]$ ) is fast and unpredictable. New organizations (r) that are able to make quick decisions inevitably reach a phase (K) of increased connections, investments, rules, efficiencies, and
Fig. 1. The pattern of dynamics in an adaptive cycle, showing how the two phases where change happens $(\Omega$ and $\alpha)$ are influenced by conditions and processes at small and large scales. Adapted from Chaffin and Gunderson 2016.

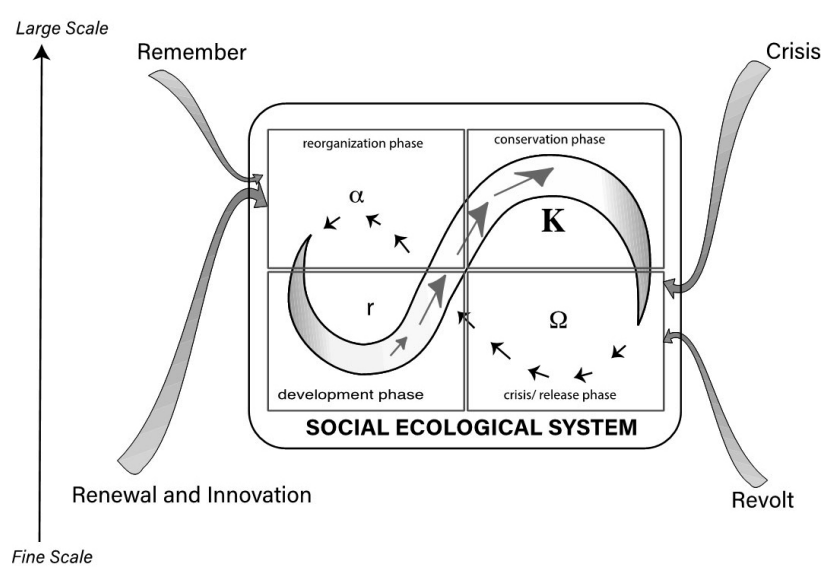

${ }^{1}$ Fenner School of Environment and Society, The Australian National University, Canberra, Australia, ${ }^{2}$ CSIRO Sustainable Ecosystems, Australia, ${ }^{3}$ Center for Limnology, University of Wisconsin-Madison, Madison, WI, USA, ${ }^{4}$ Beijer Institute of Ecological Economics, Royal Swedish Academy of Sciences, ${ }^{5}$ Stockholm Resilience Centre, Stockholm University, ${ }^{6}$ Department of Environmental Sciences, Emory University, Atlanta, GA, USA, ${ }^{7}$ Environmental Sciences, Wageningen University, ${ }^{8}$ School of Sustainability, Arizona State University, Tempe, Arizona, USA, ${ }^{9}$ Waterloo Institute for Social Innovation and Resilience and School for Environment, Enterprise and Development, University of Waterloo, Kitchener, ON, Canada 
an atrophying capacity for sensing external changes. Innovation and resilience are low. Such "architecture of simplicity" (Miller 1993) is highly correlated with organizational collapse (Miller 1992, Hurst 1995). A small disturbance precipitates a collapse, which then moves into a phase of reorganization.

Over longer terms, cycles are part of a spiral trajectory. Following collapse, true novelty may emerge, along with prominent legacy effects. For instance, European history since the Medieval Period illustrates that upon crises such as the ones triggered by pandemic, floods, and other disasters, wealth inequality in societies typically increased, as the elite used their leverage to strengthen their position (which appears to be happening now in the USA). By contrast, in times and places when wealth equalizing institutions were already in place, the opposite happened and crises led to a reduction of wealth inequality and an increased freedom for all people (Curtis et al. 2016, Van Bavel and Curtis 2016). Thus, it is an intricate combination of novelty and legacy that shapes history, with crises as occasional catalysts of change; and crises favor those with the means and capacities to adapt.

We advocate interpreting the current pandemic as part of an adaptive cycle because the forthcoming reorganization phase will be critical to how the new system is structured and behaves. It is during this brief period that new things become possible; new species that could never have become established in a mature ecosystem; new ideas, structures, processes in socioeconomic systems. In the near future the globe will enter a new growth phase, either a version of the existing unsustainable system or a different one.

For an alternative system to emerge it needs to be imagined and articulated before the collapse phase ends. Only by doing that can the elements of such a new system be given due consideration and incorporated in the ensuing phase of reorganization. It will be too late to wait until the collapse is over; reorganization to bring the system back into its existing form will begin while the collapse happens, and without a clearly articulated alternative the opportunity for introducing change will be lost. In line with the evidence on spiraling cycles, analyses of reorganizations following crises in regional case studies show that reorganizations are usually strongly shaped by existing plans (Curtis et al. 2016). Being prepared for the looming re-organization is therefore critical.

If it is essentially the existing system that emerges from the reorganization, its incompatibility with the dynamics and constraints of the natural world and its propensity to increase inequity and conflict will lead to another version of the present calamity. The cycle becomes a spiral and intensification of the drivers will likely result in the next cycle being faster. The magnitude of a disturbance needed to precipitate collapse will decrease, and the consequences will be greater. If it is a deliberately transformed system that emerges its future will depend, first, on what has been included in the transformation process. And, second, it will depend on the way the system is guided into the future. Resilience principles embedded in an adaptive pathway approach - testing interventions, learning how the system responds, keeping options open as the system changes through time, avoiding directions that lead into undesirable states-will enable it to cope with uncertainty and levels of future disturbance that would otherwise precipitate collapse.
The wording in Figure 1 comes from analyses of a variety of different systems and captures how the current $\Omega$ phase happened and the balance of the two scales of influence that will be needed in the forthcoming $\alpha$. For $\Omega$ the crisis is the virus, and the "revolt" disturbances are the cascading effects on society, economics, and the environment. In $\alpha$ "remember" will be the strong influence of those currently in charge and "renewal and innovation" will be the set of proposed changes in the drivers of the global socialecological system.

What are these drivers? What are the drivers that determine human well-being and environmental sustainability, and which of them need to be changed?

\section{UNDERLYING DRIVERS IN THE PRESENT GLOBAL SYSTEM THAT CAN AND SHOULD BE CHANGED}

Distilling assessments of human needs from the eight UN Millennium Assessment Goals and Maslow's hierarchy of needs (Maslow 1943), four highly valued features in a society emerge: security, health, food, and shelter. The determinants of these features include a just and stable society, control of human diseases, a climate regime conducive to agricultural productivity, population density, housing availability, income, and employment/occupation opportunities. Most of them have threshold levels that, if crossed, lead to major changes in society. Refining this list is a prerequisite for identifying the important underlying drivers, a tentative list of which follows.

\section{(i) The economic system}

- A change from continuous growth with GDP as its measure of progress to a system based on increasing inclusive wealth (Arrow et al 2012): Maximizing money flow (GDP) is leading to declining levels of natural and social capital stocks on which future wealth and human well-being depend.

- A change from rewarding individualism with attendant high inequity to one based on collective action and collaboration: Inequality has been identified as a cause of the disproportionate effect of COVID-19 on the poor in all societies, and a cause of its spread (Ahmed et al. 2020). More generally, inequity is a cause of international conflicts, refugees, and mass migration, exacerbated by global warming. We distinguish here between inequality (an objective measure of unequal distribution) and inequity, a normative term that evokes an unfair or unjust distribution of privileges across society and that is the cause of resentment and unrest (Hamann et al. 2018).

- Transformation from short-term maximization of profits to long-term sustainability; transformation from the fossil fuels energy industry to renewable energy.

\section{(ii) Homogenization}

Two aspects of a homogenized global economy significantly reduce resilience to crises (such as Covid-19).

- Response diversity in food supplies: Genetically uniform crop varieties have no response diversity to different pests and diseases or environmental extremes, and the capacity to maintain total food supply is declining. As one example, Greece is estimated to have lost $95 \%$ of its broad genetic stock of traditional wheat varieties after being encouraged 
to replace local seeds with modern varieties (Heal et al. 2004). Similarly, loss of locally manufactured goods and access to a variety of international sources reduces resilience at the local scale.

- Management of food, water, and other ecosystem services strives to reduce short-term variation: Constriction of shortterm variance causes long-term variability to increase (Bode's law of control systems) and thereby increases fragility of ecological production (Carpenter et al. 2015). The resilience of food, water, and other ecosystem services can be increased by diversifying production systems and allowing for variability among them.

\section{(iii) Human population growth, size and densities}

Barrett et al. (2020) show that for most of the world, human attitudes and practices in regard to family size are socially embedded, suggesting it is possible for societies to reduce their fertility rates without experiencing a loss in well-being, which leads to the next driver.

\section{(iv) Consumption patterns, human ethics, and behavior}

A change is needed in what is admired by others and that drives self-esteem and social status; a change from consuming and owning material goods to sharing, helping others, and maintaining our life-support system. The growing shift toward stewardship at local scales and support for it at a global scale (Chapin et al.2010) is a positive sign that such a change is feasible.

\section{(v) Governance}

At all scales our current predicament reflects a lack of adaptive governance (Folke et al. 2005, Chaffin and Gunderson 2016), in particular polycentric governance (Ostrom 2010), in which disturbances are addressed at the scale of the problem with connections vertically across scales and horizontally to allow for learning and experimentation. In a crisis, top-down governance responses exacerbate some problems (e.g. authoritarianism; ineffective, one-size-fits-all policies) and purely bottom-up approaches are also ineffective. The challenge is how to implement polycentric governance at a global scale.

\section{PROSPECT}

This tentative short list illustrates the kinds of changes needed in the drivers of global dynamics for the world to transform to a trajectory of sustainable human well-being. The question is how and by who? Where are the leverage points (Meadows 1999)? Transformability, the capacity to undertake transformation, has three components (Walker and Salt 2012):

1. Accepting that such a change is necessary (getting beyond the state of denial), often a major stumbling block but which can occur rapidly as a result of a crisis;

2. Experimenting with and finding new options (the alpha phase);

3. Getting the necessary structures, processes, and support (political, financial, policy) to implement them (the growth phase).

A number of issues that have surfaced during this COVID crisis have raised questions about limitations and stumbling blocks to how to achieve the necessary changes in the drivers. Its focus on the natural alternation between periods of stagnation and periods of crisis-related transformation makes resilience theory an appropriate framework to address such urgent questions. Can looking at the current global turmoil through the lens of an adaptive cycle help us understand and address pressing concerns? Here are a few such questions for which further exploration may allow filling in the picture of the current phase of global turmoil and reorientation:

1. What are the causes and effects of populist and isolationist leaders such as those of the USA, the UK, Brazil, and Hungary, and how do they relate to drivers (i), (ii) and (v), the negative consequences of the present economic system, homogenization, and governance?

2. What drives the rise of "anti-science" and how does it affect policies involving the trade-off between short-term economic loss and longer term, potentially devastating loss? What kinds of interventions can help reverse this trend of rewarding individualism and rising inequity (driver (i))?

3. What shapes educational reforms, and in the long run what are its effects on questions (1) and (2) and hence most of the drivers, especially the effects of educating women on family size and population growth, outlined in driver (iii)?

4. What has been the role of the rise of social media over the past decade on (1) and (2), particularly in regard to human ethics, behavior, and the need for adaptive governance (iv and v), and how may this unfold as digital literacy and fact checking improve?

5. How do overt and hidden power structures shape institutional reforms upon the crisis via effects on the economic system, the consumption ethic, and top-down vs. inclusive governance (i, iv, and v), and how do these power structure effects influence future resilience, inequality, and sustainability?

6. What can we learn from observed disruption of global supply chains about characteristics that would allow resilience at local and national scales in the face of future shocks (v)?

7. How does the further rise of China as a Superpower asserting itself on the global stage affect existing international institutions and relations with its neighbors and the USA and EU, in ways that will make changes in the drivers (i) through (v) more or less difficult?

We conclude by emphasizing again that the window of opportunity presented by the COVID crisis for transformational change will be short. Most of those currently in charge are doing their best during this phase of unravelling to make sure that in the forthcoming phase of reorganization the top-down "remember" influence will return the global system as much as possible to how it was before the crisis. How to get a co-ordinated bottom-up activity in "renewal and innovation" that is as strong as the remember influence is the big challenge. It will need to be via a growing, widespread discussion about changes that are necessary for the future (and in many instances, present) wellbeing of society and the globe, and how they may be instituted. Will the COVID shock be of sufficient magnitude to get a sufficient number of those currently in charge beyond their state of denial? 
Responses to this article can be read online at:

http://www.ecologyandsociety.org/issues/responses. $\mathrm{php} / 12072$

\section{Acknowledgments:}

We acknowledge the helpful comments of the review editor in developing the final version of the paper.

\section{Data Availability:}

Datal code sharing not applicable

\section{LITERATURE CITED}

Ahmed, F., N. Ahmed, C. Pissarides, and J. Stiglitz. 2020. Why inequality could spread COVID-19. The Lancet 5(5):E240. https://doi.org/10.1016/S2468-2667(20)30085-2

Arrow, K. J., P. Dasgupta, L. H. Goulder, K. J. Mumford, and K. Oleson. 2012. Sustainability and the measurement of wealth. Environment and Development Economics 17:317-353. https://doi. org/10.1017/s1355770x12000137

Barrett, S., A. Dasgupta, P. Dasgupta, W. N. Adger, J. Anderies, J. van den Bergh, C. Bledsoe, J. Bongaarts, S. Carpenter, F. S. Chapin III, A.-S. Crépin, G. Daily, P. Ehrlich, C. Folke, N. Kautsky, E. Lambin, S. A. Levin, K.-G. Mäler, R. Naylor, K. Nyborg, S. Polasky, M. Scheffer, J. Shogren, P. Søgaard Jørgensen, B. Walker, and J. Wilen. 2020. Social dimensions of fertility behavior and consumption patterns in the Anthropocene. Proceedings of the National Academy of Sciences 117 (12):6300-6307. https://doi.org/10.1073/pnas.1909857117

Carpenter, S. R., W. A. Brock, C. Folke, E. H. van Nes, and M. Scheffer. 2015. Allowing variance may enlarge the safe operating space for exploited ecosystems. Proceedings of the National Academy of Sciences 112(46):14384-14389. https://doi.org/10.1073/ pnas. 1511804112

Chaffin, B. C., and L. H. Gunderson. 2016. Emergence, institutionalization and renewal: rhythms of adaptive governance in complex social-ecological systems. Journal of Environmental Management 165:81-87. https://doi.org/10.1016/j.jenvman.2015.09.003

Chapin III, F. S., S. R. Carpenter, G. P. Kofinas, C. Folke, N. Abel, W. C. Clark, P. Olsson, D. M. Stafford Smith, B. Walker, O. R. Young, F. Berkes, R. Biggs, J. M. Grove, R. L. Naylor, E. Pinkerton, W. Steffen, and F. J. Swanson. 2010. Ecosystem stewardship: sustainability strategies for a rapidly changing planet. Trends in Ecology and Evolution 25:241-249. https://doi. org/10.1016/j.tree.2009.10.008

Curtis, D. R., B. van Bavel, and T. Soens. 2016. History and the social sciences: shock therapy with medieval economic history as the patient. Social Science History 40:751-774. https://doi. org/10.1017/ssh.2016.30

Folke, C., T. Hahn, P. Olsson, and J. Norberg. 2005. Adaptive governance of social-ecological systems. Annual Review of Environment and Resources 30:441-473. https://doi.org/10.1146/ annurev.energy.30.050504.144511
Gundersen, L. H., and C. S. Holling, editors. 2002. Panarchy. understanding transformations in human and natural systems. Island, Washington, D.C., USA.

Hamann, M., K. Berry, T. Chaigneau, T. Curry, R. Heilmayr, J. G. P. J. G. Henriksson, J. Hentati-Sundberg, A. Jina. E. Lindkvist, Y. Lopez-Maldonado, E. Nieminen, M. Piaggio, J. Qiu, J. C. Rocha, C. Schill, A. Shepon, A. R. Tilman, I. van den Bijgaart, and T. Wu 2018. Inequality and the biosphere. Annual Review of Environment and Resources 43:61-83. https://doi.org/10.1146/ annurev-environ-102017-025949

Heal, G., B. Walker, S. Levin, K. Arrow, P. Dasgupta, G. Daily, P. Ehrlich, K.-G. Maler, N. Kautsky, J. Lubchenco, S. Schneider, and D. Starret. 2004. Genetic diversity and interdependent crop choices in agriculture. Resource and Energy Economics 26:175-184. https://doi.org/10.1016/j.reseneeco.2003.11.006

Hurst, D. K. 1995. Crisis and renewal: meeting the challenge of organizational change. Harvard Business School Press, Boston, Massachusetts, USA.

Maslow, A. H. 1943. A theory of human motivation. Psychological Review 50(4):370-396.

Meadows, D. 1999. Leverage points: places to intervene in a system. Sustainability Institute, Hartland, Vermont, USA.

Miller, D. 1992. The Icarus paradox: how exceptional companies bring about their own downfall. Business Horizons 35(1):24-35 https://doi.org/10.1016/0007-6813(92)90112-M

Miller, D. 1993. The architecture of simplicity. Academy of Management Review 18(1):116-138. https://doi.org/10.2307/258825

Ostrom, E. 2010. Beyond markets and states: polycentric governance of complex economic systems. American Economic Review 100(3):641-672. https://doi.org/10.1257/aer.100.3.641

Van Bavel, B., and D. Curtis. 2016. Better understanding disasters by better using history: systematically using the historical record as one way to advance research into disasters. International Journal of Mass Emergencies \& Disasters 34:143-169.

Walker, B. H., and D. Salt. 2012. Resilience practice: building capacity to absorb disturbance and maintain function. Island, Washington, D.C., USA. https://doi.org/10.5822/978-1-61091-231-0 